\title{
PROCESSES OF ICE DEFORMATION WITHIN GLACIERS
}

\author{
By the late Max Harrison Demorest
}

\section{Introduction (by Dr. Eleanora B. Knopf, Stanford University, California)}

In December 194I the late Dr. Max H. Demorest presented a paper on "Processes of Ice Deformation within Glaciers" before the Annual Meeting of the Geological Society of America.* This paper embodied ideas on the mechanism of ice flow that Dr. Demorest had developed during the course of an intensive study of ice fabric both in the field and in a low-temperature laboratory at Yale University. It will be recalled that in one or two brief abstracts Dr. Demorest mentioned his concept of instantaneous recrystallization, but gave no explanation of this process.

These ideas were only preliminary results of a brilliant research program that was, unfortunately for science, cut short by the untimely death of Lieutenant Demorest, who was killed in Greenland on 30 November 1942, while on a rescue expedition in the service of the Army Air Corps of the United States Army.

The notes of his I94I paper were found among field and laboratory notes by Dr. Demorest that were turned over to me by Dr. Demorest's widow. They include a much fuller explanation of his concept of instantaneous recrystallization than found in any of his other publications. It seems that it would be very desirable and useful if these brief notes could be published, so that glaciologists might see what was in Dr. Demorest's mind.

Thanks to the Geological Society of America, Yale University, the National Research Council, and the Society of Sigma Xi, I have been privileged to spend the last couple of years in an ice box, and in the field where studies could be made of the processes by which ice flows.

We are all interested in the flow of rock, and those who are concerned with glaciology are particularly interested in the flow of the rock called ice.

Flow of ice has long been recognized, and is now generally accepted as a fact by practically all glaciologists. But there is still a question as to the mechanism of this flow. Since the days of Tyndall and Forbes regelation has been known as a process promoting ice flow. And, thanks to T. C. Chamberlin (who denied that ice movement is a matter of flow), we have also the concept of idiomolecular transfer, that is, sublimation and intergranular transfer of ice molecules from points of lesser to points of greater molecular stability.

Quincke (followed by R. S. Tarr and von Engeln) argued for the importance of foam-cell melting, that is, intergranular melting enhanced by the presence of weak salt concentrates between grains. And finally, from the experiments of McConnel and Kidd, it is recognized that slip on the basal planes of ice grains might be a significant factor in flow.

Now there are both inductive and deductive reasons for believing that the first two of these four processes-regelation and idiomolecular transfer-occur throughout large parts of most glaciers. It is probable, however, that they are of greatest effectiveness in the pervious younger ice of the névé fields. Such ice, shown in Fig. I (p. 212), is made up of small, approximately equidimensional, grains that fit one next to the other like the elements of a mosaic.

Grains average about one eighth of an inch $(3.18 \mathrm{~mm}$.) across. This ice is characteristically porous, the many bubbles being interconnected so as to give a high degree of permeability, Fig. 2 .

The studies of Seligman demonstrate that differential motion within this sort of ice is similar to the flow that occurs when buckshot is poured out of a container, the individual ice granules rotating and slipping one past another. Obviously, however, the motions are very slow. Rotation is favored by the equidimensional character of the grains, for only relatively small amounts of ice need be evaporated or melted at points of contact in order to allow rotational movement. Also,

\footnotetext{
* Bulletin of the Geological Society of America, Vol. 52, No. 12, Pt. 2, 1941, p. 1897.
} 
the very porous nature of the ice favors both rotation and the processes of idiomolecular transfer and regelation-especially the former.

Probably the process of foam-cell melting also occurs in all parts of a glacier, at least to the extent that there are impurities within the ice. Its effect, however, can only be one of lowering the melting point at intergranular contacts and for that reason it only serves to supplement regelation -and like regelation it is probably of most importance in ice of this character where approximately equidimensional grains allow great ease of rotation.

Let us next consider ice that has suffered considerable movement. Obviously something has happened to it. It is metamorphic ice, as shown in Fig. 3. This specimen was cut from near the terminus of a glacier on Mt. Rainier. A similar section was cut from a Greenland iceberg, a piece of which was shipped to me by Commander Smith of the International Ice Patrol.

These specimens are characterized by large, irregularly shaped grains. Dimensions of grains may vary from $\frac{1}{4}$ in. $\left(6.35 \mathrm{~mm}\right.$.) (and even smaller) to extremes of 6 in. ( $15^{2.4} \mathrm{~mm}$.). Most generally, however (at least in the Mt. Rainier ice), they range from $\frac{1}{2}$ to 2 in. (12.7 to $50.8 \mathrm{~mm}$.).

The question of how grains grow in size and irregularity unfortunately remains unanswered (or at least it is only partly answered), although it is intimately connected with the question of how movement occurs. Fig. 4 emphasizes what is meant by irregular grains and Fig. 5 shows irregular grains produced by experimental deformation in the laboratory. This was originally a specimen of névé such as shown in Fig. $\mathrm{x}$. Another characteristic of metamorphosed ice is the frequent occurrence of strain shadows or undulatory extinction. Fig. 6 is a photomicrograph of a thin section of a single ice crystal, measuring about 2 in. in its longest dimension, mounted between two pieces of plate glass and compressed under 10 atmospheres for $\mathrm{I}_{7} \mathrm{hrs}$. $40 \mathrm{~min}$. Minor extinction irregularities are seen. Fig. 7 , showing the same crystal after 42 hrs. deformation, exhibits a high degree of irregular extinction.

Now these characteristics, the irregularity of grain shapes and the occurrence of undulatory extinction, have led to a new concept that may account in part for the mechanisms of ice flow. This is the concept of instantaneous recrystallization, as I have called it. (I will be glad for suggestions of a better name.)

In presenting this concept I must emphasize that it can be regarded only as a partial explanation of ice flowage. As already mentioned, regelation and idiomolecular transfer (and foam-cell melting) are important processes; and in the young ice of the névé where granular rotation may readily occur they are probably the most important processes.

However, in metamorphic ice, shown in Fig. 3 (where grains are so very irregular and so greatly interlocked), there is little possibility for granular rotation. Regelation and idiomolecular transfer probably occur, but they are apparently unable to relieve the deformational stresses except where rotation is favored by relatively non-interlocking grains. Thus, within metamorphic ice, stresses of sufficient magnitude to cause deformation of the crystallographic lattice accumulate and this accumulation is followed by instantaneous recrystallization.

I may explain instantaneous recrystallization as a phenomenon similar to mechanical twinning and the polymorphic changes that occur within many substances.

We know for example that a cleavage rhomb of calcite may be twinned by the application of mechanical force-and that at a certain critical temperature quartz is altered from one crystal form to another. In both cases the change results from an increase in the potential energy of the crystal lattice. The lattice becomes energized to an unstable condition, and there immediately occurs an instantaneous reorganization of the lattice.

In less exact terms we can say that the atoms became uncomfortable under the conditions of increased energy, and that at a certain critical point of discomfort they suddenly decide to reorganize themselves into new and more comfortable arrangements. Now I believe that something similar to this occurs within ice. There is a difference, however, in that neither twinning nor polymorphic changes take place. First the ice is strained-the lattice is distorted (as shown by undulatory extinction) and its potential energy is increased. At some critical point, however, the strain is 
too much, and as a result there is an instantaneous reorganization of the atoms-a reorganization that simply duplicates the original lattice structure in a more comfortable position but without twinning or polymorphic change.

Now it would be difficult for me to demonstrate conclusively that this actually occurs, yet it seems very reasonable in view of the fact that strain of the crystal lattice always accompanies deformation but does not generally lead to a diminution of grain sizes. Strain of a crystal lattice, if carried to an extreme, would lead to failure by fracture (which does sometimes occur). But the fact that it does not occur generally is interpreted to mean that stresses are more often relieved by instantaneous recrystallization.

The strain of the crystallographic lattice in ice is thought to involve slip on the basal planes. This is indicated by the fact that the "wave-front" of a strain shadow always lies parallel to the "c-axis" (others have offered a similar explanation for the strain of quartz). Apparently intracrystalline differential motions occur on basal planes as basal lamellae are warped. It is the same sort of slip that occurs between cards when a pack of them is bent, or the sort that occurs to produce drag-folds in the bending of an anticlinal structure. The bending, however, can go only so far, for as such deformation proceeds the lattice acquires increased potential energy and recrystallization results.

This explanation of strains within ice crystals confirms the concept of basal-plane slip as an important process in the flow of ice. In addition, however, basal-plane slip is of even greater importance in places where conditions of long-continued uniform stresses have been operative. For reasons that cannot be explained in the time available for this talk, the process of instantaneous recrystallization favors reorientation of grains into a position such that the basal planes lie in the planes of flow or of shear. Obviously, in such a position a grain will be readily deformed by basal slip alone. There will be no necessity for lattice deformation and instantaneous recrystallization, unless the direction of shear is altered.

Fabric analysis of glacier ice has shown that in many places such parallelism between basal crystallographic planes and the direction of shear is characteristic.

To summarize thus far: There are four important processes involved in the flow of ice. These are :

(I) regelation, (2) idiomolecular transfer, (3) basal-plane slip, and (4) instantaneous crystallization. These are operative in all parts of a glacier but are of greatest importance in the névé where approximately equidimensional grains are free to rotate.

Foam-cell melting may be regarded as an auxiliary process aiding regelation.

The third process, a basal-plane slip, operates wherever the basal planes of ice grains lie close to the plane of shearing stress, and it is also operative where deformation causes distortion of the crystallographic lattice of an ice grain.

The fourth process-instantaneous recrystallization - causes the atoms of a deformed ice grain to become reorganized in a more comfortable position in which the stress is relieved. This process is of chief importance where ice grains are so very irregular and so greatly interlocked that there is no freedom for intergranular rotation.

MS. received 22 fuly 1952

Comments on this paper by J. W. Glen are printed on p. 219.-Ed. 


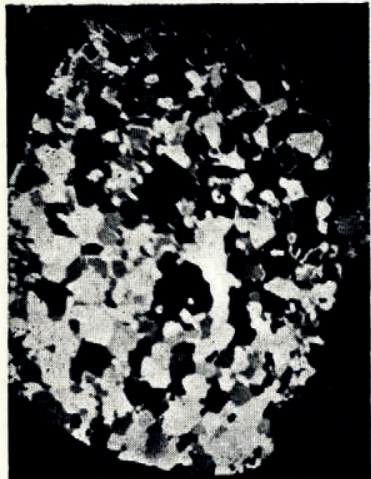

Fig. I

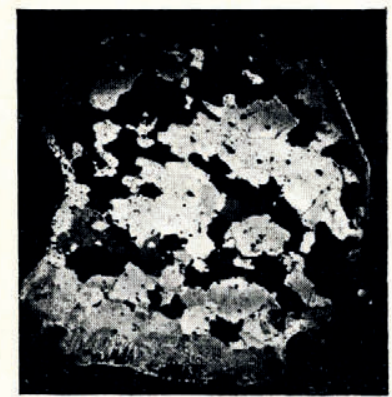

Fig. 3

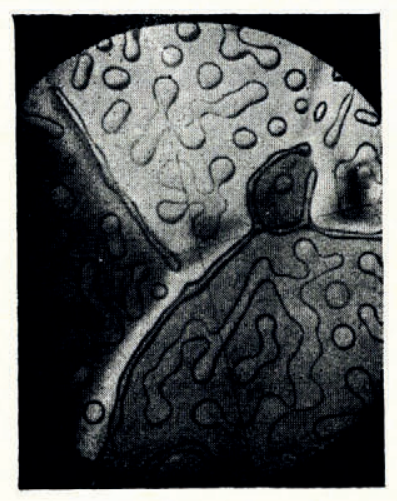

Fig. 2

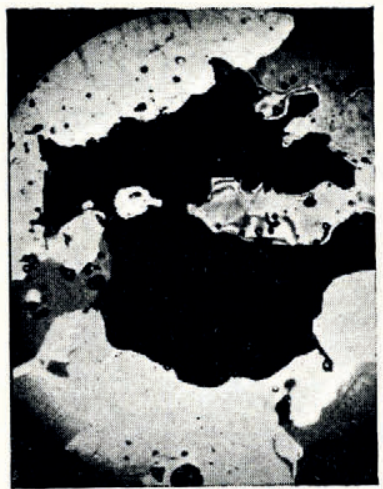

Fig. 4
Fig. I. Photomicrograph of a section of Mt. Rainier névé $\times I \frac{1}{2}$, under polaroid

Fig. 2. thotomicrograph of Mt. Rainier névé showing bubbles. $\times 3^{\circ}$

Fig. 3. Metamorphic ice from the snout of the Nisqually Glacier, Mt. Rainier. General view photographed under 15 inch polaroid

Fig. 4. Irregularly shaped grains from glacier ice in the snout of the Nisqually glacier, Mt. Rainier. Photographed under polaroid. $\times I \frac{1}{2}$

Fig. 5. Mt. Rainier névé, deformed in compression in the low-temperature laboratory. Shows irregular re-entrants in grain boundaries. Photographed under polaroid. $\times 30$

Fig. 6. Photomicrograph of a thin section of a single ice crystal mounted between two pieces of plate glass and compressed under Io atmospheres. Photograph taken after 17 hours and 40 minutes deformation. Shows minor extinction irregularities in the darkcolored central grain. $\times 3$

Fig. 7. The same crystal after 42 hours deformation, showing a high degree of irregular extinction. $\times 3$

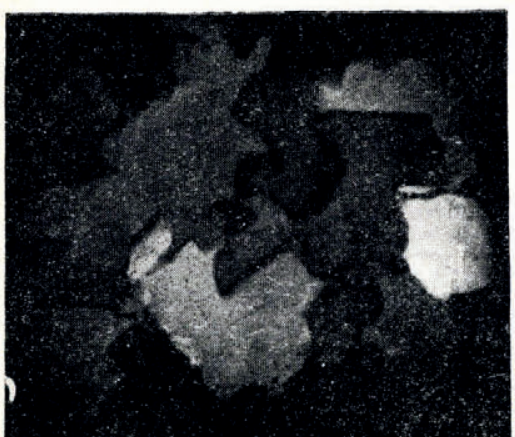

Fig. 5

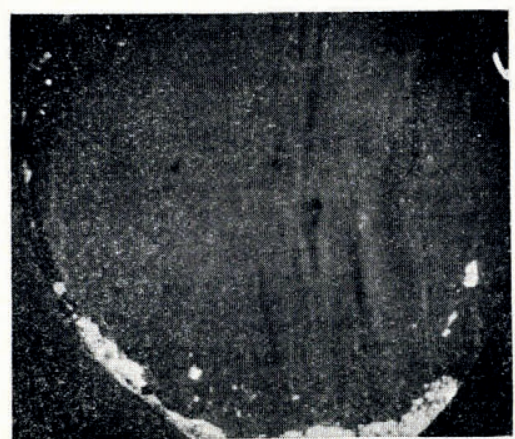

Fig. 6

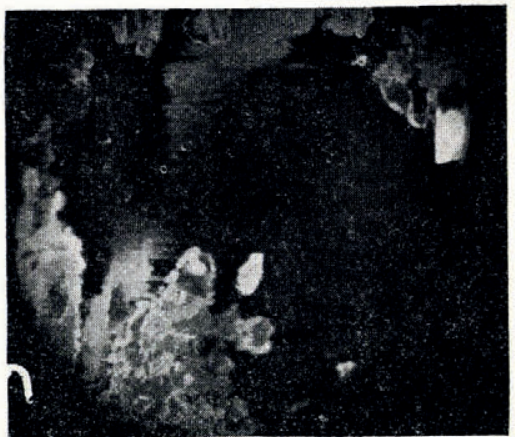

Fig. 7 